\title{
OS AMBIENTALISTAS BRASILEIROS, os DIREITOS SocIAIS E A NATUREZA
}

\section{Lúcia da Costa Ferreira}

RESUMO: Este artigo tem por objetivo analisar as diferenciações internas ao ambientalismo, em seus modos de analisar os direitos sociais frente à conservação da natureza. Há entre eles grupos eminentemente politicos, que propõem a organização da sociedade para reivindicar direitos referentes à qualidade dos sistemas sociais. Outra categoria reivindica mudanças profundas nos códigos e valores que sustentam a relação da sociedade com a natureza. Em ambos os casos ć possivel reconhecer uma tentativa de consenso na construção de um projeto histórico social que se estabelece na alteridade ao nacional desenvolvimentismo, com vistas a uma sociedade mais justa, igualitária c ecologicamente sustentável.

PAlavras-Chave: ambientalismo, participação política, direitos sociais.

\section{APRESENTAÇÃO}

Este artigo pretende abordar um tema extremamente fecundo, tanto do ponto de vista intelectual, quanto político, e que tem merecido atenção especial de alguns autores caros ao ambientalismo, de modo a compartilhar o reconhecimento da necessidade de um novo projeto social e de uma teoria baseada em categorias positivas que substituam esse sentimento coletivo de esgotamento das antigas utopias, de descrença frente a um mundo aparentemente fragmentado, sem sentido. 
O tema abordado aqui pode ser resumido como a preocupação com o processo atual de construção de um novo projeto social, que se propõe histórico, construído cotidianamente em oposição a um dado projeto hoje predominante. A idéia força que sustenta sua identificação política é uma proposta de expansão no campo dos direitos, de modo a resolver o impasse da predação dos ecossistemas no mundo todo. Essa expansão não se restringe contudo, à formulação de um código legal cada vez mais rígido e bem intencionado, mas que não tenha fôlego e legitimidade para ser incorporado à cultura política de uma dada sociedade.

Há duas propostas sendo germidadas no âmbito do ambientalismo. Uma delas, aquela de mais fácil decodificação, pretende a expansão do significado do direito, até hoje restrito à idéia de carências materiais, para incorporar a qualidade ambiental ao universo da cidadania, em nome de uma boa sociedade, cujo pilar seria o progressivo bem estar social. A outra proposta, bem mais ousada porque não depende apenas de recursos financeiros $e$ vontade política, pretende uma tal extensão da esfera dos direitos que pressupõe uma mudança $\mathrm{cm}$ seu conteúdo, nos seus fundamentos. Da pretensão de expansão da cidadania a todos os homens, cujo princípio normativo é moral e baseia-se em sua humanidade exclusiva, caminha-se para uma expansão no sentido de abarcar todo o mundo da vida. A esfera da cidadania coincidiria com um campo de relacionamentos alargado entre todos os seres vivos. Sua universalidade funde-se com a biosfera.

Essa última proposta, que pressupõe uma nova subjetivação da natureza, é contruída na oposição a um tipo de projeto histórico social que se sustenta em um agir instrumental-orientado-a-objetivos. A questão que dá suporte a alguns desses setores do ambientalismo indaga sobre as possibilidades e limites das tentativas de sacralização da biosfera, como que buscando um reencantamento do mundo.

O ambientalismo contemporâneo, justamente por seu caráter multissetorial (Galtung, 1984; Viola, 1992), apresenta inúmeras facetas e 
tendências. Mas, apesar disso, ou talvez por isso mesmo, apresenta-se na maioria das vezes como uma possibilidade de projeto social, inacabado, incompleto, reconhecidamente em construção; mas arrisca-se de qualquer maneira, a prever um reordenamento do mundo e das relaçòes entre a sociedade e a biosfera, de modo a buscar novas mediações para a resolução de conflitos, depois do esgotamento desse papel tradicional no âmbito do Estado moderno.

O projeto ambientalista, não obstante as limitações que the são inerentes, apresenta uma grande vantagem diante da estagnação atual, já que por conta de suas próprias premissas, é obrigado a enfrentar as relações possiveis entre os homens contemporâncos e a naturcza e acaba tendo que repensar ao mesmo tempo, as relações entre eles mesmos, em sua vida em sociedade.

Antes de mais nada, seria conveniente lembrar que o ambientalismo brasileiro foi transformando-se através de sua atuação nas duas últimas décadas, de modo a criar uma identidade cultural e política mais ou menos bem delimitada. Nos anos de 1980 , a politização da degradação social e ambiental do município de Cubatão, no litoral do estado de São Paulo, por exemplo, apontava para uma experiência emblemática do país, que poderia ser caracterizada como anômica em sua relação com a natureza, tornada objetivada por um projeto nacional de desenvolvimento econômico e social, sem dúvida alguma vitorioso em sua ação voltada à criação de uma identidade nacional, baseada no nacional-desenvolvimentismo (Miranda, 1979; Ferreira, 1993).

Naquela ocasião fora possivel observar um acordo nacional, que ultrapassava classes ou interesses setoriais e apontava para a supremacia do desenvolvimento à conservação dos ecossistemas nacionais. Não havia normas ou regras que organizassem a predação. A questão ambiental não tinha sido ainda verdadeiramente incorporada à vivência nacional e carecia de qualquer sentido para a maioria da opinião pública. Cubatão demonstra- 
va, de modo exemplar e com uma carga de dramaticidade ímpar, que a preocupação ambiental importada por alguns intelectuais urbanos desde a década anterior, era até então simples retórica.

Esse mundo vivo, "natureza" pensada como cultura, isto é, "tomada pelo homem, socializada, incorporada aos mundos humanos, vivida como símbolos, como suporte, ao mesmo tempo, do ato de significar" (Brandão, 1994, p.72), inexistia como problema. A cultura nacional, tão impregnada pelo drama da pobreza e do desenvolvimento, não conseguiu naquele momento nominar o nexo doloroso entre ambos com a natureza.

Hoje a situação observada é de uma anomia parcial. A questão ambiental institucionalizou-se (Ferreira, 1992; Viola, 1991, 1992; Viola \& Leis, 1992), o país convive com uma legislaçào ambiental relativamente bem elaborada e existem inúmeros casos, nos quais foi possível estabelecer um acordo, mesmo que parcial, entre diferentes segmentos sociais com vistas à recuperação de alguma área degradada, ou para conservar uma coleção de ecossistemas considerada prioritária.

Se hoje o ambientalismo já se consolidou no país através de inúmeras vitórias sociais e jurídicas no campo dos direitos, em contrapartida, a grande questão continua sendo a legitimidade da conservação e recuperação ambientais, para a cultura política brasileira de um modo geral. $O$ projeto ambientalista, apesar das conquistas importantes do final dos anos de 1980 e início dos de 1990, não conseguiu sequer, pelo menos até aqui, uma performance ao menos semelhante ao projeto que lhe é adversário, ou seja, o nacional desenvolvimentismo.

Como conseguir essa legitimidade em um contexto democrático, para que o projeto ambientalista nào acabe por reivindicar um Estado policial, capaz de fiscalizar de modo mais eficaz as áreas passíveis de conservação e punir aqueles que, independentemente da condição social, insistam em manter relações predatórias com os ecossistemas que se encontram em seu entorno? Essa talvez seja a grande preocupação consensual que percorre 
vários setores do ambientalismo, independentemente de suas diferenças internas.

As tentativas de encontrar respostas a essa indagação quase consensual irào justamente diferenciar a ação ambientalista. Como já foi dito, alguns reivindicam uma mudança política e transitam no eixo de relações Estado e Sociedade Civil. Outros reivindicam uma mudança cultural, onde o nexo da relação entre os homens e destes com o mundo natural seja modificado em sua essência, segundo uma reformulaçào radical nos códigos e valores que organizam a base de nossas relações com os outros seres vivos.

Essa diferenciaçào na ação política ambientalista é, por sua vez, a preocupação desse artigo, como possibilidade de compreensão desse projeto social, cuja especificidade está sendo definida na justa relação cotidiana entre abordagens muitas vezes antagônicas, outras complementares, mas que se influenciam mutuamente. De qualquer forma, tais diferenças talvez sejam úteis também para delinear os contornos desse ator contraditório do ponto de vista sociológico e político, mesmo que as divergências entre tendências nào possam ser totalmente resolvidas, nem tampouco seja possível encontrar caminhos definitivos para ultrapassá-las nesse momento. Com esse propósito, o texto foi estruturado em dois grandes ítens que mapeiam as questões centrais que diferenciam a ação ambientalista hoje. Assim é possível reconhecê-las através do contraponto entre os campos por onde transitam tendências diferenciadas, suas características políticas principais e os desafios que estruturam sua ação.

\section{OS DIREITos SOCIAIS COMO PROBLEMA}

O ambientalismo brasileiro modificou-se nos anos de 1980 sob forte influência de outros movimentos sociais, que naquela época estabeleceramse como um formato alternativo palpável de organizaçào política. Em um mesmo movimento, os sindicatos fortaleceram-se depois das greves no 
$\mathrm{ABC}$ paulista $\mathrm{e}$ as demandas populares invadiram o espaço público (Durhan, 1984; Moisés, 1985; Nunes \& Jacobi, 1985; Telles, 1987; Krischke, 1987; Scherer-Waren, 1987; Scherer-Waren \& Kriscke, 1987; Cittadino, 1988; Jacobi, 1989; Nunes, 1989). As aspiraçōes por uma sociedade justa e igualitária ganharam forma na reivindicaçào de direitos diversos, expandindo o espaço jurídico formal, através de conquistas importantes na Constituição de 1988 e traduziram-se "na formação de sujeitos políticos hoje reconhecidos como interlocutores legítimos no jogo político nacional" (Telles, 1994, p.44).

Nesse periodo o desafio da cidadania de modo geral era construir um sentido de pertencimento, sem o qual homens e mulheres não poderiam reconhecer-se como cidadãos, pois sempre foi difícil que os direitos funcionassem como referências normativas a identidades $\mathrm{em}$ uma sociedade que insiste em destituir a todos e a cada um de um lugar de reconhecimento: para além das consequências do aumento da pauperização, do desemprego e subemprego, o resultado escandaloso das políticas de saúde, educação, infra-estrutura, ao invés de organizar as bases de uma vida digna, armam um espelho perverso que projeta as imagens da exclusão (Telles, 1994).

$\mathrm{O}$ ambientalismo emergente no país teve que conviver com a ausência de espaços de reconhecimento e de vínculos propriamente civis, que seriam traduzidos pela dificuldade de formular os dramas cotidianos públicos e privados na linguagem dos direitos. Sua herança imediata foram códigos morais da vida privada, revestidos de ampla utilidade para ganhar o espaço político, disputando assim códigos de legitimação com a linguagem reconhecida no diálogo formal com o Estado, através da participaçào política em organismos tradicionais. Apesar de sua intenção verbalizada em diferenciar-se de outros movimentos, mostrava-se impossível não levar $\mathrm{cm}$ conta que "a negação de direitos, o não reconhecimento do outro como sujeito de interesses e aspirações legítimas afeta a sociabilidade, cultura e identidades" (Telles, 1994, p.45). 
Por outro lado, em um país onde se engatinha na construção de patamares mínimos de cidadania, em que o sentido da responsabilidade pública está ausente da cultura política, em que os direitos estão longe de se constituir como parâmetro na definição das políticas que afetam a vida coletiva, "a pauta pós-welfare state em um contexto de crescente desregulação da economia haverá de aprofundar ainda mais desigualdades e exclusões" (Telles, 1994, p.47).

Os regimes militares, por sua vez, deixaram de herança à sociedade brasileira nos anos de 1980, a utopia popular de uma nação de trabalhadores construída em um cenário de incerteza e anomia. "Tem os direitos, mas basicamente os deveres de cidadão, não os que nascem no território do país simplesmente, ou os que se submetem às leis da comunidade nacional", mas aqueles que trabalham e contribuem de alguma forma para a renda nacional. A idéia de trabalho confunde-se assim, na vida privada e no plano jurídicoinstitucional. Esta concepção de cidadania, segundo Alba Zaluar (1992, p.120-121), está na base de uma estratégia do Estado corporativista de integração seletiva (Offe, 1984; Jacobi, 1989), ou seja por setor profissional, da massa trabalhadora ao universo da cidadania, fazendo dela um parceiro legítimo nos debates e conflitos de interesses.

Para o pensamento acadêmico que tem grande influência sobre a política social e sobre a definição da pauta de reivindicações de movimentos sociais, a idéia básica da conceituaçào de pobreza é a de carência material, que marcou o pensamento técnico sobre a intervenção do Estado no tecido social durante todo o período autoritário, quando a política social caracterizava-se como assistencialista, paternalista e clientelista e baseava suas ações em valores de caridade e filantropia (Zaluar, 1992).

A interpretação de carência como falta material dificulta a compreensào dos vários aspectos dos direitos - civis, políticos e sociais - entrelaçados mesmo quando se trata das políticas sociais. Nessa perspectiva, a desigualdade surge no plano social, apenas como diferenças materiais, sem vinculá- 
la também a outras desigualdades, como as políticas e jurídicas. Do ponto de vista da política social efetivada, a inclusão indiscriminada de todos os pobres, que marcou o sistema seletivo e corporativo no periodo autoritário, nào significou em hipótese alguma um tipo de integração universalista, fruto de direitos reconhecidos de cidadania. Ao contrário da fase assistencialista que atendia todos os pobres, sem discriminá-los por categorias, agora, o Estado Todo Poderoso é associado à implantação da justiça social. Nos anos de 1980, a mesma concepção assistencialista penetrou nos inúmeros e descontínuos programas oficiais de assistência aos pobres, apesar da retórica da cidadania.

Assim, o problema central na história recente da relação do Estado brasileiro com a sociedade e suas demandas é a inexistência do reconhecimento oficial e extraoficial da dimensão concreta da noção de cidadania. Em outras palavras, o desconhecimento deste espaço público, onde as pessoas não se submetem, mas participam dividindo benefícios e responsabilidades caracterizou amplos setores sociais, independentemente de escolaridade ou renda, ou ainda vinculação ideológica. Em uma das versões, aquela preferencial dos gestores convencionais, a noção de direitos está praticamente ausente, pois os papéis sociais que a caracterizam ocupam a posição de contribuinte, que cumpre seus deveres para com o Estado. Em outra versão, aquela extraoficial convencional, a noção de deveres também desaparece, em função de uma ampliação ilimitada dos direitos e os pobres são vistos como "vítimas da sociedade". O Estado, por sua vez, ora é colocado na posição do perseguidor, ora na de salvador. Essa confusão entre o público e o privado esvazia o papel do cidadão e as demandas daí resultantes misturam-se entre interesses coletivos e pessoais (Zaluar, 1992, p.119).

As mudanças no significado da pobreza provocadas pela cultura autoritária, junto ao imaginário daqueles que utilizam a retórica da defesa da política social voltada ao atendimento dos setores mais pobres não passam de um tipo de armadilha, cuja retórica vale-se das justificativas a programas 
de estímulo ao crescimento da economia, baseadas no argumento da expansão da massa economicamente ativa e dos consequentes benefícios do welfare state ao universo dos trabalhadores. Esse talvez tenha sido um dos nós mais complicados para o ambientalismo emergente desatar.

A agenda política nacional tem sido assim definida fora do espaço de reconhecimento dos direitos sociais e políticos. $\mathrm{O}$ sentido de pertencimento ao universo da cidadania ficou restrito à esfera de produção da riqueza do país, ainda que limitado às carências materiais básicas da sociedade. Deste continuum de pertencimento estão excluídos grandes contingentes sociais: o nào contribuinte inexiste como cidadão pertencente a uma dada Nação. Para essa estranha identidade nacional a qualidade ambiental aparece como mais um fator de exclusào, nunca como uma referência normativa a mais no processo de consolidação de direitos sociais.

Não há como negar todavia que o universo da cidadania tem sido lentamente ampliado, graças às lutas sociais através dos tempos. As mulheres, os não proprietários e os estrangeiros foram paulatinamente incorporados ao espaço público ocupado pelo cidadão. Cidadania em contrapartida, não pode significar apenas uma concepção de igualdade meramente jurídica: o acesso às oportunidades, garantida por uma sociedade política . O universo da cidadania só tem sentido se o cidadão exigir a igualdade através da participação, da criação de novos direitos, novos espaços e de novos acordos em torno de objetivos comuns, movimentando o processo em constante mudança de constituição de novos atores políticos (Benevides, 1994, p.14).

Uma sociedade profundamente marcada pela desigualdade e pelos desequilíbrios sócio-econômicos e político-culturais carrega em si uma definiçào de cidadão como portador de direitos e deveres exageradamente discriminatória. No Brasil, sem dúvida, existem cidadãos de diversas categorias. Existem inclusive aqueles, cuja convivência com índices alarmantes de contaminação ambiental configuram uma situação de ausência total de direitos 
(Ferreira, 1993). Essa herança política e cultural deixada ao ambientalismo aprofundou dilemas e dificultou sua atuação política. Os fantasmas da exclusão e discriminação criaram barreiras quase intransponiveis entre militantes e a opinião pública, que há dez anos se debatem em torno de uma falsa polêmica entre qualidade ambiental e bem estar social.

Entretanto sua tarefa apresenta-se como uma via de mão dupla. De um lado os ambientalistas têm tentado articular ambos os fatores da equação, qualidade ambiental e bem estar social, no âmago da cultura política. De outro, sua tarefa mais árdua é, tal qual outras formas de mobilização, formar cidadãos, vistos como alguém que exerce direitos, cumpre deveres ou goza de liberdade em relação ao Estado e é também portador de um papel social, através da participação direta no exercício do poder político. Nesses termos, os direitos políticos de que são portadores adquirem sentido em torno da organização para reclamar os direitos sociais (Benevides, 1994). A cidadania reivindicada sustenta-se pelos princípios da democracia, significando necessariamente conquista e consolidação social e política. Esta exige pois, instituições, mediações e condutas próprias, constituindo-se na criação e expansão de espaços sociais de luta e na definição de instituições reconhecidas para a expressão pública de novos direitos adquiridos.

Os contornos políticos do espaço público próprio do ambientalismo pode ser caracterizado de inúmeras maneiras. Dentre elas há pelo menos duas que ocupam posição de destaque. Em primeiro lugar, em um país onde as carências relativas à pobreza em áreas urbano industriais ocupam o espaço preferencial de constituição do universo da cidadania, invadindo ora a retórica oficial, ora a agenda dos movimentos reivindicatórios, a saturação ecossistêmica que caracteriza o território nacional aparece à opinião pública como reivindicação de forte conteúdo ideológico, como se o bem estar do cidadão representasse a antítese da conservação dos sistemas naturais.

É como se a "cidadania dos deveres" (Zaluar, 1994, p.119) fosse levada às últimas consequências. A perspectiva corporativista, construída em 
um tipo de relação com o Estado - seja ele colocado na posição do salvador, todo poderoso, seja na posição do perseguidor, excludente - que opõe os contribuintes aos que não pagam impostos, é imediatamente trasportada para as relações com as outras espécies que povoam a biosfera. Para o trabalhador, que contribue com os cofres públicos, os programas de conservação consomem recursos para proteger outras formas de vida, mas deveriam ser direcionados para permitir-lhe o acesso progressivo e ilimitado ao bem estar social. Quando muito aceita financiar programas oficiais de assistência à pobreza voltados ao universo de excluídos do mundo do trabalho e da produção.

Em uma autofagia singular, a sobrevivência de um fator da equação qualidade ambiental e bem estar social - só seria possivel com o consumo inexorável e a destruição do outro. De qualquer forma, este forte conteúdo ideológico, compartilhado por amplos setores da sociedade, obscurece a noção dos direitos socialmente construída, dificultando a expansão da agenda política de modo a incorporar demandas ainda pouco visíveis no tecido social. A extensão progressiva e ilimitada do bem estar social para atingir o universo nacional esbarra nos argumentos acerca da escassez de recursos para mantê-la (Ophuls, 1977) e gastou-se tempo e esforços demasiados a fim de estabelecer e negociar patamares aceitáveis, do ponto de vista da sustentabilidade, para as expectativas de pobres e ricos. Diante do drama social vivido pelo país o conteúdo dessa discussào sempre pareceu exageradamente artificial.

Em segundo lugar, esse forte conteúdo ideológico que reveste as carências que ultrapassam a reprodução da mão de obra aponta ainda para a personalização das relações sociais, como elemento complicador da ação política organizada em torno da qualidade ambiental. Reivindicações sobre a qualidade da água para abastecimento, a manutenção de remanescentes florestais, dentre outras, fogem à compreensào imediata das necessidades 
básicas de uma sociedade que se reconhece como excludente, dramaticamente pauperizada e a cada dia mais voltada ao mercado mundial.

Tal qual a maioria das carências não materiais verbalizadas, ou tornadas visíveis pelas classes médias, ou por movimentos étnicos, de gênero e de liberação dos costumes, o sentido para a mobilização ambientalista é buscado na vida privada. $\mathrm{Na}$ medida em que ganham o espaço público, interferem enormemente nas condutas voltadas à participação política, diluindo a agenda reivindicatória, dificultando o estabelecimento das parcerias e, finalmente, restringindo o espaço de legitimação do tema. Uma sociedade, cuja maioria esmagadora é obrigada a administrar orçamentos domésticos escassos e convive cotidianamente com a ausência de cidadania, tende a aceitar também a não se reconhecer como portadora do valor universal conferido à vida.

Na realidade, como pano de fundo a estas dificuldades políticas encontra-se um panorama de possibilidades e limitações enfrentadas pelas condutas políticas voltadas à qualidade ambiental, na articulação de outros setores da sociedade brasileira que ultrapassem as classes médias urbanas, principalmente de seus setores mais intelectualizados. Solo obviamente fecundo para o desenvolvimento de opções existenciais e muitas vezes politicas, por um modo de vida calcado em valores pós materialistas.

Os desafios das condutas políticas voltadas à qualidade ambiental alojam-se de fato, na dinâmica mais ampla de uma sociedade, cuja expressão pública de novos direitos convive com a negação cotidiana do universo da cidadania, através da institucionalização de práticas excludentes, violentas e arbitrárias. Segundo Vera Telles $(1987,1994)$, o eventual atendimento a reivindicações está longe de consolidar os direitos, como referência normativa nas relações sociais, de tal forma que conquistas anteriormente alcançadas podem ser anuladas, sem que isso suscite o protesto e a indignação da opinião pública. 
As práticas de organizaçào, representação e negociação generalizamse com dificuldade, para além do espaço de organização política, por "conta de uma gramática social muito excludente que joga maiorias fora do poder de interpelação de sindicatos, partidos e organizações civis" . A conquista do espaço público e a descoberta do sentido da ação coletiva para ampliar o universo da cidadania e descortinar horizontes possíveis já vem comprometida pela convivência diária com os indices alarmantes de pobreza que destroem projetos, desorganizam formas de vida e comprometem o futuro de qualquer significado positivo (Telles, 1994).

Em contrapartida, o ambientalismo carrega ainda a dificuldade de ser reconhecido como um todo, onde se misturam valores extremamente diferenciados e tendências muitas vezes contraditórias. As tendências do ambientalismo que optaram por transitar no espaço público da cidadania diferenciam-se em pelo menos duas categorias, de acordo com as estratégias utilizadas. Um primeiro grupo caracteriza-se pela militância, já que é herdeiro da tradição socialista e anarquista de décadas anteriores. Seu principal desafio é o diálogo com os outros movimentos por direitos sociais, sindicais e civis e o conteúdo de sua proposta é mais voltado à compatibilização da qualidade ambiental ao bem estar social, como sendo o próximo baluarte a ser conquistado na construção da cidadania.

Em uma outra direção, mas ainda transitanto em torno do mesmo eixo de açào, há um segundo grupo que se caracteriza como grupo de pressão e seu diálogo preferencial é com o Estado, como forma de resolver rapidamente os problemas causados pela cultura política nacional. Seu principal desafio é fortalecer o próprio cacife político, através do impacto de suas propostas junto a formadores de opinião $\mathrm{e}$ da opinião pública intelectualizada dos grandes centros de um modo geral. O conteúdo de sua proposta é baseado em uma promessa de eficiência na utilização dos recursos e sua garantia é técnica e científica, uma vez que pressupõem o esvaziamento do discurso mobilizatório. 
Em uma direção diametralmente oposta, encontram-se aqueles grupos que reivindicam uma reformulação total no campo dos direitos e um reordenamento da cultura nacional. É o caso por exemplo, daqueles que se autodenominam os últimos românticos. Apesar de suas dificuldades no trato com a opinião pública "esclarecida" dos grandes centros urbanos e da quase inexistência de diálogo com os excluídos, vêm conseguindo grande visibilidade, expandindo sua esfera de influência, justamente porque transitam na esfera da vida privada e o conteúdo de sua proposta reveste-se de um significado que nega o politico. Exatamente por isso, os desafios que enfrentam são de outra natureza: sua ação desloca-se da esfera política para a cultural.O fato de, em muitas circunstâncias confundirem-se com os grupos militantes, já que muitos deles são herdeiros das tradições anarquista e da teologia da libertação, faz com que a opinião pública relacione-os como sinônimo de "ambientalismo".

Nesse amálgama de tensões, parcerias muitas vezes circunstanciais e interlocução intensa e cotidiana entre tendências o projeto ambientalista vai tomando forma e, em marchas e contramarchas procura definir o seu papel social, organizando condutas e estalecendo contornos para expectativas sociais e políticas futuras.

\section{A RAZÃo INSTRUMENTAL E ANTROPOCÊNTRICA COMO PROBLEMA}

Movimentando-se em uma outra direção, a vertente neoromântica do ambientalismo coloca como problema de fundo a razão instrumental, base das relacões modernas entre os homens e destes com a natureza.

Seria conveniente lembrar antes de mais nada, que os setores do ambientalismo contemporâneo preocupados com esse tema são na verdade aqueles herdeiros dos movimentos de contracultura que deixaram sua marca nos anos de 1960. John MacCormick (1992) lembra que o ambientalismo floresceu com grande intensidade nesse período, nos países onde havia um 
intenso clima de ativismo político, provocado por inúmeros movimentos sociais por direitos civis.

Não que houvesse laços formais definitivos entre aquele ambientalismo $\mathrm{e}$ as outras acões mobilizatórias que pretendiam expandir os direitos sociais e civis, já que os valores propagados eram muitas vezes diferenciados e as clientelas também se distinguiam. Mas todos eles fortaleciam-se e influenciavam-se mutuamente, em um espaço público construído em torno de um clima de protesto contra os valores políticos e sociais estabelecidos, contra a legitimidade dos arranjos políticos e das instituições sociais e econômicas. A inquietação diante da autoridade constituida e a sensibilidade aos problemas gerados por uma sociedade altamente industrializada, urbanizada e discriminatória criaram em várias partes do mundo uma clientela receptiva junto às camadas médias $\mathrm{e}$ intelectualizadas dos grandes centros urbanos.

Esse clima cultural e político propiciou um casamento perfeito entre o ambientalismo emergente com a contracultura, de tradição anarquista, profundamente antiindustrial, crítica à ética do trabalho, ao consumismo e aos valores materiais, mas também a uma dada racionalidade baseada na ciência e na técnica que produzira atrocidades como a guerra do Vietnã e os danos ecológicos que se espalhavam pelo mundo todo. $\mathrm{O}$ ambientalismo emergente nos países ricos frequentou a escola moral e antiestablishment do movimento bippie no final da década de 1960, para quem o retorno ao mundo selvagem representava o único caminho para recuperar valores não materialistas em uma sociedade perversa (MacCormick, 1992, p.77).

Segundo MacCormick (1992) essa proximidade levou o ambientalismo a despedir-se de suas origens preservacionistas ou conservacionistas, para restabelecer-se como movimento histórico:

"(..) O Novo Ambientalismo era ativista e politico. Muitos dentre os grupos
preservacionistas mais antigos perseguiam objetivos essencialmente filantrópi-
cos, enquanto os conservacionistas baseavam seus argumentos na ciência eco-
nômica; em contraste, os novos ambientalistas buscavam um impacto mais diTemáticas, Campinas, 4(7):31-68, jan./jun. 1996 
retamente politico. Sua mensagem era de que a catástrofe ambiental só poderia ser evitada através de mudanças fundamentais nos valores e instituiçōes das sociedades industriais.(...) O Novo Ambientalismo pode ser visto como parte de uma transformação social mais ampla que ocorria então na sociedade ocidental.(...) O Novo Ambientalismo era um movimento politico e social, e as questões que levantou eram, em uiltima análise, universais" (MacCormick, 1992, p.77).

Paehlke (1989), por sua vez, relaciona a emergência de um novo ambientalismo a uma mudança radical no enfoque conservacionista em direção a uma preocupação com a degradação ambiental (pollution). Esta mudança foi provocada por preocupações mais ou menos consensuais durante os anos de 1970 com o crescimento populacional, a produção e distribuição de alimentos, além do grande tema da depleção dos recursos naturais, principalmente os energéticos.

Outra distinção importante que o autor (Paehlke, 1989, p.15) faz entre o conservacionismo da década de sessenta e o novo ambientalismo emergente na década posterior é o abandono de um tipo de gospel of efficiency, que propagava argumentos científicos, principalmente econômicos, para promover uma racionalização técnica para o uso dos recursos. Para ele, a era da conservação caracteriza-se pela eficiência, pelo uso racional dos recursos e o uso absoluto sobre a natureza.

Pachlke (1989) assinala quatro características importantes desse novo ambientalismo. Em primeiro lugar, de meados dos anos de 1960 até o presente, desde aqueles caracterizados como antipoluição até aqueles antinucleares, ou organizados em torno da questão dos resíduos tóxicos, todos passaram a ser eminentemente políticos e ideológicos. $\mathrm{O}$ ambientalismo passava a compreender desde então uma dimensão antitecnológica. Em segundo lugar, o ambientalismo contemporâneo afastou-se das florestas e de outras áreas selvagens distantes dos centros urbanos. Sua preocupação com a proteção da vida selvagem só tem sentido a partir de então, na medida em que esta é fundamental para a viabilidade da biosfera global. Em terceiro, os 
grupos ambientalistas questionam, em última instância, a lógica privada das decisões e o modelo convencional de produção, baseado no crescimento econômico ilimitado. Quarto, o movimento ambientalista caracteriza-se por colocar em dúvida o north american consumer lifestyle.

Por outro lado, a preocupação dos ambientalistas neoromânticos contemporâneos é o nexo necessário para conferir algum sentido a esse "desmesurado e corajoso salto de retorno da sociedade à natureza" (Brandão,1994, p.72), que continua fazendo parte de seu projeto nos dias atuais, visto agora de forma mais ampla. $O$ mundo natural deveria ser incorporado ao campo dos diálogos e ao eixo dos direitos, através das possibilidades de substituição da perspectiva histórica própria da razão ocidental, instrumental, antropocêntrica, por um tipo de razão próxima à oriental, baseada em uma visão holística, intersubjetiva, onde a linearidade do pensamento é substituida pela idéia de teia.

Seu grande tema, embora em nenhum momento ele seja verbalizado, é também, tal qual o Novo Ambientalismo que se estabelecia nas décadas de 1960 e 1970 de que fala MacCormick, o sentimento coletivo de revolta contra o exercício do controle social inerente às sociedades capitalistas industrialmente desenvolvidas.

Habermas (1980, p.314) dizia acerca disso, em seu diálogo com Marcuse, que o agir racional-com-respeito-a-fins é, segundo sua estrutura, o exercício do controle. Por isso, a racionalização das relaçòes da vida, segundo padrões pré-estabelecidos, significam o mesmo que a institucionalização de um tipo de dominação irreconhecível enquanto política. Compartilhando uma parcela da tese de Marcuse, diz que o grande problema da dominação nas sociedades contemporâneas não está mais no âmbito da exploração do trabalho, mas na generalização progressiva da racionalização para todas as esferas da vida.

Talvez o conceito de razão técnica seja uma ideologia, já que a própria técnica é um projeto histórico-social de controle sobre a natureza e 
sobre os homens. Tal qual se viu no Brasil do período do nacionaldesenvolvimentismo, o projeto predominante no seio da cultura política da época mantinha-se em uma promessa de dupla face: de um lado uma riqueza escatológica; de outro, menos visível, a dominação, que se sustentava na "manutenção de um sistema que pode se dar a liberdade de fazer do crescimento das forças produtivas, ligadas ao progresso técnico-científico, o fundamento de sua legitimação" (Habermas, 1980:314).

Paradoxalmente para Habermas e Marcuse, a dominação pode perder seu conteúdo ideológico na consciência das pessoas, pois sua legitimação assumiu um novo caráter, que se baseia na referência a sempre crescente produtividade do trabalho e domínio progressivo sobre a natureza, resguardando o direito individual a um bem estar social também sempre crescente, praticamente ilimitado. Talvez seja possível imaginar que essa promessa, progressivamente institucionalizada, dê também à experiência anômica de natureza sua chance de legitimação.

De qualquer forma, a idéia força é que os princípios da ciência e da técnica foram estruturados a priori, de modo a poderem servir de instrumentos conceituais para um universo de controle produtivo sobre a natureza. Tais instrumentos, que levaram a uma dominação cada vez maior dos recursos naturais, tornaram-se as condições necessárias e suficientes para uma dominação também cada vez maior sobre a sociedade. Hoje, essa dominaçào perpetua-se e garante a formidável legitimação do poder político em expansão, que absorve e penetra praticamente todos os domínios da vida social. A racionalização de Max Weber não é apenas um processo a longo prazo de modificação das estruturas sociais, mas aparece ao mesmo tempo como a manutenção de uma dominação objetivamente obsoleta, incoberta pela invocação de imperativos técnicos, que não passam por sua vez, de uma racionalidade de manipulação, de dominação (Habermas, 1980).

Se esse fenômeno que liga a ciência e a técnica a um projeto de mundo, ao qual Marcuse engata a sua análise da sociedade, está relacionado a um 
determinado tipo de interesse e a uma dada situação histórica, então, a emancipação só é possível através de uma mudança radical dos seus princípios. Esse é o pressuposto que sustenta a produção da maior parte dos autores e lideranças políticas seduzidos por uma proposta de humanização da ciência e da técnica e de outros ainda que chegam a acalentar esperanças secretas no seu fim.

Somente um tipo de conhecimento capaz de criar novos sentidos para o mundo natural e, dessa forma, capaz ao mesmo tempo de criar um novo projeto para a sociedade como um todo, poderia colocar fim à manipulaçào técnica dos recursos naturais, estabelecendo uma relacão de parceria fraterna e cooperativa, em substituição à atual objetivação e instrumentalização das relações. Habermas (1980, p.318), por exemplo, analisa a proposta de Marcuse de mudar a esfera da interação, de uma esfera da produção e do trabalho, para uma intersubjetiva, comunicativa. A idéia de que uma subjetividade da natureza ainda agrilhoada não possa emergir antes de a comunicação entre os homens torne-se livre, essa idéia em si mesma continua a ter uma força de atração toda especial.

Só se os homens pudessem comunicar-se sem coação e se cada homem pudesse reconhecer-se no outro, só então a espécie humana poderia eventualmente reconhecer a natureza como um outro sujeito. Não a natureza como o seu outro, como pretendia o Idealismo, mas a si mesma como sendo o outro desse sujeito. A alternativa para a técnica existente, o projeto da natureza enquanto parceira no jogo, ao invés de objeto, refere-se a uma estrutura alternativa do agir: a interação simbolicamente mediatizada, em oposição ao agir racional-com-respeito-a-fins.

O problema dessa proposta é que esse projeto alternativo deveria ser um projeto "da espécie humana no seu todo e não de uma época isolada, de uma classe determinada, de uma situação que pode ser ultrapassada" (Habermas, 1980, p.318). Em outros termos, estamos pensando em um ator muito especial, que não é historicamente ultrapassado, pois não é social- 
mente definido e que impede a manifestação de qualquer peculiaridade: a espécie, biologicamente constituída. A maior dificuldade apontada por $\mathrm{Ha}$ bermas (1980, p.319) é determinar de modo exato o significado de uma expansão da racionalidade incorporada nos sistemas do agir com-respeito-afins até tornar-se uma forma de vida, uma "totalidade histórica" do mundo da vida.

Seria conveniente problematizar alguns passos que compõem essa proposta ousada. Em primeiro lugar, seria bom lembrar, juntamente com o próprio Habermas (1980; 1990), que Weber usou o conceito de racionalização para interpretar as consequências do progresso técnico-científico sobre as instituições que sustentaram a modernização. Segundo Habermas, os pares de conceitos que Weber utiliza giram em torno do mesmo problema, que seria reconstituir a mudança institucional provocada pela ação racionalcom-respeito-a-fins ou, dito de outro modo, ação racional-orientada-a- objetivos, como por exemplo, status e contrato, comunidade e sociedade, grupos formais e informais, cultura e civilização, sacralização e secularização, dentre outros, de modo a dar conta das inúmeras tentativas de mudança, mesmo que parcial, do quadro institucional de uma sociedade tradicional, para uma sociedade moderna.

Essa preocupação tem grande validade para os intelectuais ambientalistas, já que se busca a lógica que sustentaria a emergência tímida de uma nova sociedade, baseada em relações inusitadas entre os homens e destes com o mundo natural. A racionalização passa a ser hoje então, um ponto importante que merece atenção especial. Habermas propõe, incorporando as críticas de Marcuse a Weber, cujo eixo central aponta a despolitização de suas hipóteses, trabalhar com a idéia força de racionalização, mas lembrando que ela se apresenta sempre como parcial e, principalmente, através da distinção fundamental entre agir racional-com-respeito-a-fins, seja o agir instrumental, seja a escolha racional, seja a combinação de ambos e o agir comunicativo. 
Habermas $(1980 ; 1988)$ entende a ação instrumental como sendo aquela regida por preferências formadas através das regras técnicas baseadas no conhecimento empírico. A escolha racional (Friedland, 1974; Roemer, 1985; Carling, 1985; Przeworski, 1988), por sua vez, é regida por estratégias baseadas no conhecimento analítico e implica derivações das regras de preferência, baseadas em valores e máximas universais. Em qualquer um dos casos, a ação racional-orientada-a-objetivos realiza os fins definidos em dadas condições. Ao passo que o agir instrumental organiza os meios adequados, segundo regras de controle da realidade, a ação estratégica só depende de avaliações corretas, ou adequadas das alternativas possíveis para atingir objetivos previamente estabelecidos.

A ação comunicativa, por sua vez, que representa sua grande proposta alternativa à razão instrumental e transformou-se posteriormente em teoria (Habermas, 1988), é um tipo de interação intersubjetiva, mediada simbolicamente. Este tipo de açào é regida por normas previamente estabelecidas por acordo entre pelo menos dois atores, que definem expectativas recíprocas e principalmente, precisam ser compreendidas e reconhecidas pelos polos da relação (Habermas, 1980, p.321). Em outros termos, na ação comunicativa os participantes são sujeitos orientados ao entendimento, ou restringem-se ao consenso previamente alcançado. O exxito desta ação, expectativa esta que lhe confere sentido, só é possivel através da categoria do entendimento, ou da possibilidade de consenso. Nos casos onde um deles é possivel, os atores sào conduzidos a um acordo, que por sua vez depende única e exclusivamente das negociações entre as partes (oferta c postura frente à oferta), sendo impossível qualquer tentativa do uso da força. Do ponto de vista da ação comunicativa, não há interesse maior, pelo menos em um primeiro momento, no significado da fala. Ou seja, não há interesse analítico predominante naquilo acerca do qual se produz um acordo. A preocupação central não é o conteúdo do consenso, mas as condições formais de obtenção dele (Habermas, 1989). 
Apesar de que nem todas as atividades constitutivas da vida social são comunicativas, as várias tradições sociológicas da teoria da ação, de Weber a Parsons, culminando com Marcuse e Habermas concordam com alguns pressupostos básicos. Em primeiro lugar, todos optam por uma análise centrada no processo de entendimento entre sujeitos, ou seja, baseada na perspectiva interna do ator. $A$ ação social então, pode ser analisada como a realização de um plano que se sustenta em uma interpretação. Em segundo lugar, a coordenação das ações pressupõe um acordo, ou seja, uma interpretação comum, fundada no reconhecimento intersubjetivo de pretenções de validade, ou de êxito. Finalmente, todos os autores acima reconhecem que qualquer ação baseada em princípios normativos, ou em instituições reconhecidas, serão evidentemente mais sólidas e duradouras, quanto melhor integradas forem as orientaçòes valorativas, normativamente exigidas, com as constelações dadas de interesses (Habermas, 1989, p.486).

No caso específico do ambientalismo atual, independentemente das tendências internas, essa perspectiva proporciona algumas vantagens, principalmente quando se pretende imaginar esse ator tão especial c contraditório do ponto de vista sociológico, desvendando, mesmo que parcialmente, seu papel social, os componentes normativos de sua ação e o espaço adequado para sua atuação na criação de indentidades que fogem daquelas estabelecidas no âmbito do Estado.

Nessa perspectiva apresenta-se em primeiro lugar, a questão da alteridade. Se o espaço público intersubjetivo de comunicação só é possível como manifestação das diferenças e se a questão é a construção de uma relação intersubjetiva com o mundo natural, porque surgiriam propostas que margeiam um reencantamento do mundo? Esse seria o único, ou o caminho mais adequado para, em contraste à instrumentalização da racionalidade moderna, refundar o sentido das relações entre os homens, em sua vida social e destes com a biosfera? Sob a lógica da razão orientada-aobjetivos, a ciência e a técnica venceram a natureza exterior, em uma batalha 
travada desde a pré-história, mas que se acelerou gravemente a partir da revoluçào industrial, com o advento da modernidade (Thomas, 1988).

Assim como o contrato social, a Declaraçào dos Direitos do Homem ignora e silencia acerca do mundo natural. Esta foi pronunciada em nome da natureza humana e em favor dos excluídos do universo da cidadania. $\mathrm{O}$ direito agiu sempre a partir de um sujeito de direito, cuja noção progressivamente ampliou-se. O contrato social (Rousseau, 1978) encerrara-se em si mesmo e deixara fora do mundo uma coleção infindável de seres que eram reduzidos ao estatuto de objetos, passiveis de apropriação. Os sujeitos do conhecimento e da ação poderiam gozar de todos os direitos; seus objetos, evidentemente de nenhum (Serres, 1991).

A proposta do projeto ambientalista de reordenar o direito de modo a incorporar ao universo da cidadania outros seres vivos que partilham a biosfera com o homem, só seria possível segundo sua concepção, se a ilusão ocidental de um mundo dividido entre um polo humano de pura subjetividade e um polo "natural" de pura objetivaçào fosse substituída por uma perspectiva, onde o mundo natural fosse trazido à esfera da subjetividade:

"Alargar o lugar social do diálogo até o ponto em que outros seres dotados de outras sensibilidades (...) possam participar de uma mesma rede de comunicações conosco (...). Assim a natureza e seus seres individuais, apropriados até aqui de acordo com nossos interesses, devem ser libertados de serem considerados como uma dimensão outra da existência - o que não significa negar a alteridade (...) - caracterizada por uma passividade essencial e pré-suposta, sobre a qual é possivel o pleno exercicio do dominio bumano através do trabalho (...) regido pela utilidade social. Devem ser assim liberados para converteremse numa largada dimensão de diálogo e comunicação com/entre os bumanos. Desde logo a dominação arbitrária de um polo ativo e pensante sobre o outro, passivo e pensado, poderia passar a ser a comunicação e a troca de dons entre dois polos, aos quais caberia o desafio de estabelecer os novos termos de uma lógica e de uma ética de reciprocidades"(Brandão, 1994, p.76-77).

Talvez a preocupação básica da concepção neoromântica relacione-se a uma incapacidade da cultura moderna de pensar o mundo natural através 
de princípios sociais, ou "pensar a natureza como símbolo e o sentido do simbólico como algo essencialmente social". A grande conquista atual e, ao mesmo tempo, a tarefa do ambientalismo estaria circunscrita então, ao âmbito da capacidade criativa, já que esta não é dada ao homem a priori, mas precisa ser construída, de modo a pensar-se a si mesmo como um "misterioso milagre" de ser biologicamente uma única espécie, mas ao mesmo tempo e em um mesmo movimento, ser capaz de "produzir uma infinidade de culturas" (Brandão, 1994, p.21-22). Para Carlos Brandão (1994) essa falsa dicotomia pode ser enfrentada através da polaridade entre os modos de pensar o mundo da cultura indígena e da ocidental moderna. Essa incapacidade de pensar a natureza como algo social, seria resultado da impossibilidade de imaginar o relacionamento humano com o mundo natural como interações possíveis entre "duas categorias diversas, mas convergentes e comunicáveis, entre duas dimensōes de subjetividade" colocadas em ações recíprocas:

'Esta maneira de pensar o mundo, que torna simbólico o natural e depois pensa o simbólico como social, opõe a cultura do indio à experiência animal de lidar com o mundo. Pois neles a natureza aparece como um mero conjunto de sinais (....). Ela distancia o 'pensamento selvagem' do modo ocidental de pensar. Entre nós e a natureza, estabelecemos o fosso de uma 'dupla natureza' (...) que nos impede o simbolizar qualquer relajão com a natureza de um ponto de vista social. Somos os filhos de Prometeu, não eles.(..) Pensando como conjunção, o que nós pensamos a partir de uma inevitável disjunção, os indios movem-se em um imaginário regido de parte a parte por uma ou por intimeras formas de trocas, de reciprocidades. Isso porque, social e dotado de sentido de um lado (bumano) e do outro (natural), tudo o que se passa entre os bumanos e os outros seres (...) são trocas, porque são relacionamentos entre sujeitos, de um lado e de outro. (...) Os indios vêem-se no interior de uma trama de relafões ativas, intensionais e significativas no mundo da natureza. Isso com a condigão de sentir este mundo como alguma coisa não apenas viva, mas vitalmente significativa, algo animado e reciprocamente social" (Brandão, 1994, p.20-21). 
Esse social tem o sentido de ser possível normatizar as relações de acordo com regras, por exemplo, de aliança e parentesco. Um mundo no qual o homem inclui-se, porque pode trocar bens e símbolos, tal como é possível em sociedade: essa é aliás, a própria possibilidade da vida social. Dito de outro modo, essa consciência positiva, no sentido de que não se pensa a si mesma como a negação do que tem de natureza, cujo exemplo utilizado é a indígena, pensa com "termos intercomunicados e metaforicamente equivalentes o domínio da sociedade e o da natureza" e atribui uma mesma "qualidade de significados" às ações reciprocas de ambos os lados desta relação entre categorias diferenciadas de sujeitos (Brandão, 1994, p.2223) .

Na verdade essa discussão nos remete ao Weber da Sociologia da Religião que, ao colocar o problema da história universal, pergunta por que é que fora da Europa e dos lugares onde esta tem supremacia cultural, o desenvolvimento científico, o artístico, o político e o econômico não seguem as vias da racionalização características do ocidente? Lembrando que racionalização foi o processo de desencantamento que fez com que a desintegração das concepções religiosas gerasse uma cultura profana, podemos resumí-lo, tal qual Horkheimer em parceria com Adorno (1980), em uma única frase: "o programa do Iluminismo era o de livrar o mundo do feitiço", dissolvendo os mitos e anulando a imaginaçào, por meio do saber. $O$ desenfeitiçamento do mundo é a erradicaçào do animismo, que agora se recoloca como uma saída.

O que se pretendia erradicar era a projeção do subjetivo sobre a natureza, como forma de auto-reconhecimento, desvendando o mistério do mundo natural. Segundo o Iluminismo, seja na versão racionalista, seja empiricista, a equação anterior, cujo denominador comum à sociedade e à natureza é o sujeito, deve ser substituída pela natureza objetivada. A sociedade conhece a natureza, na medida em que pode produzi-la e reproduzi-la. De em-si, muda-se a identidade no sentido do para-si. O preço pago pelos ho- 
mens para multiplicar seu poder foi a "sua alienação daquilo sobre o que exercem poder":

'O Iluminismo se relaciona com as coisas como o ditador se relaciona com os bomens. Ele os conhece na medida em que os pode manipular. (...) É assim que o em-si das coisas vem a ser para-ele. Na modificação, a essência das coisas se revela como já sendo desde sempre a mesma, como substrato de dominação. Essa entidade constitui a unidade da natureza. Nem ela nem tampouco a unidade do sujeito eram pressupostas pela conjurafão mágica. (...) A magia não era impulsionada por um único e mesmo espirito" (Horkheimer \& Adorno, 1980, p.93-94).

$\mathrm{Na}$ medida em que todos os seres do mundo natural reduzem-se ao conjunto de todas as possibilidades de exploração, o homem atinge a identidade do si-mesmo, que não pode mais ser perdida na identificação com o outro. Essa é a "identidade do espírito e seu correlato é a unidade da natureza, diante da qual sucumbe a riqueza das qualidades" (Horkheimer \& Adorno, 1980). Assim, as múltiplas afinidades entre seres são suprimidas em nome de uma única relação entre o sujeito que confere sentido e o objeto sem sentido; entre a significação racional e o suporte dessa significação. $O$ que está em jogo nesse processo, na verdade, é a auto-preservação. A objetivação da natureza é movida pelo terror de que o si-mesmo seja novamente convertido em mera natureza. Por essa característica, todos sabem que esse processo foi levado a cabo com esforço indescritivel, já que foi necessário renunciar à pretensão da semelhança para conhecer o mundo natural.

Nessa perspectiva é possível pensar como Habermas (1990, p.14), que o processo de modernização refere-se sim a um feixe de processos cumulativos que se reforçam mutuamente, como a formação de capital e mobilização de recursos, desenvolvimento das forças produtivas e aumento de produtividade do trabalho, centralização dos poderes e formação de identidades nacionais, expansão dos direitos de participação política. Mas além disso, o processo de modernização refere-se a um dado contexto histórico do racionalismo ocidental. 
Visto desse modo, é possível entender o debate contemporâneo como a tensão entre duas perspectivas. De um lado estão aqueles que Habermas chama de neoconservadores, que generalizando uma dada leitura da Teoria da Evolução, como James Coleman por exemplo, dizem que à modernidade teriam que se seguir desenvolvimentos pós-modernos. Se a modernização autonomizou-se ao longo de sua evolução, seria possível dispensar o horizonte do racionalismo ocidental, em cujo âmbito emergiu. Onde a modernidade cultural tornou-se obsoleta, mas a modernização social progride de forma auto-suficiente, através do funcionamento da economia e do Estado, da técnica e da ciência, esta cultura exausta de auto-compreensão tem grande dificuldade para alterar suas premissas.

Em uma perspectiva completamente diferente, cujo formato político é anarquista, não existe dissociação entre modernidade e racionalização. Proclamam o fim do Iluminismo e despedem-se da modernidade como um todo, pois o racionalismo ocidental de Weber aparece como vontade de poder instrumental. Para esses autores, a modernização social não sobrevive ao fim da outra. Essa perspectiva é compartilhada por Héctor Leis (1994), quando analisa as possibilidades políticas e culturais de criação de um espaço público transnacional de governabilidade para os problemas ambientais. Segundo Leis, a dificuldade para se pensar um mundo onde o diálogo seja possivel no âmbito da diversidade cultural surge do suposto de que o processo de secularização ainda é a melhor receita disponível.

Seria conveniente no entanto, ressaltar que grandes disparidades que não podem ou não devem ser resolvidas dificultam, tal qual nas sociedades altamente sacralizadas, o surgimento do espírito da mudança, condição essencial para uma sociedade que se deseja em transformação. Para Franz Brüseke (1994) o problema da revolta só faz sentido nas sociedades modernas ocidentais, porque somente aqui a desigualdade pode ser confrontada com o principio da igualdade, teoricamente possível. 
O surgimento do indivíduo consciente de seus direitos é a condição da revolta, mas é também a condição para uma reformulação do direito em direção a uma subjetivaçào de outros seres vivos. Nas sociedades altamente sacralizadas, a existência do sagrado fixa as ações dos sujeitos, de modo a impedir as mudanças, "a chamada revolta metafísica começa somente com o início da modernidade (...), com a dessacralização radical do mundo" (Brüseke, 1994, p.120).

Essa ação sacralizadora da natureza pretendida pelos setores neoromânticos do ambientalismo atual poderia levar a uma estagnação das relações, em um patamar fechado a transformações. Talvez fosse conveniente problematizar essa perspectiva, sem pretender silenciá-la, mas sim para apontar alguns cuidados necessários à sua disseminação no seio da cultura politica contemporânea.

\section{DIVAGAÇÕES SOBRE UMA CERTA ANOMIA PARCIAL}

O problema central parece ser o sentimento atual e coletivo de perda de sentido da natureza. A natureza objetivada, resultado do processo de dessacralização, esgotou-se em si mesma. Essa natureza reconhecida como sujeito, que não é só cultura, mas também não é homem. Esse homem que é natureza, mas também é cultura, ambos exigem renominações. Esse sentimento indefinido expressa-se em processos anômicos e não pode ser considerado um problema apenas para o ambientalismo atual, nem muito menos apenas para os neoromânticos.

Segundo Habermas (1987) essa perplexidade é característica das sociedades urbano-industriais contemporâneas e deve-se ao esgotamento das utopias baseadas na sociedade do trabalho e do welfare state, comprometidos com uma vida digna para o homem e com a felicidade socialmente organizada, apresentando a ciência, a técnica e o planejamento como instrumentos promissores de controle da sociedade e da natureza. 
Contudo, precisamente essa expectativa foi por água a baixo, junto com os resultados apresentados à história. A energia nuclear, a biotecnologia, a pesquisa genética e o processamento de dados são todos intrinsecamente ambivalentes:

"Hoje as energias utópicas aparentam ter se esgotado, como se elas tivessem se retirado do pensamento bistórico. $O$ borizonte do futuro estreitou-se e o espirito da época, como a politica, transformou-se profundamente. O futuro afigura-se negativamente; no limiar do século XXI desenba-se o panorama aterrador da ameaça mundial aos interesses da vida em geral: (....) o empobrecimento estrutural dos paises em desenvolvimento, o desemprego e os desequilibrios sociais crescentes nos paises desenvolvidos, problemas com o meio ambiente sobrecarregado, altas tecnologias operadas às raias da catástrofe dão as palauras-chave que invadiram a consciência pública através dos meios de comunicação de massa. As respostas dos intelectuais refletem uma perplexidade não menor do que a dos politicos. Não é de forma alguma apenas realismo se uma perplexidade aceita temerariamente coloca-se cada vez mais no lugar de buscas de orientação que apontem para o futuro. A situafão pode estar objetivamente inintelegivel. Contudo, essa imperspicuidade é também uma função da presteźa de ação de que uma sociedade se julga capaz. Trata-se da confianfa da cultura ocidental em si mesma" (Habermas,1987, p.104-105).

Diante disso, não constitui surpresa a influência adquirida por aquelas teorias desejosas de mostrar que as mesmas "forças de incrementação do poder - das quais a modernidade extraiu outrora sua autoconsciência e suas expectativas utópicas - na verdade transformaram autonomia em dependência, emancipação em opressão, racionalidade em irracionalidade". Na cena intelectual alastra-se a suspeita de que o esgotamento das energias utópicas denuncia não apenas um dos estados de ânimo passageiros do pessimismo cultural, mas toca mais fundo. Ele poderia denunciar uma transformação da moderna consciência do tempo em geral:

'Talvez dissolva-se aquele amálgama dos pensamentos bistórico e utópico.

(...) Talvez a consciência da bistória se descarregue de suas energias utópicas: assim como no final do século XVIII, com a temporaliząão das utopias, as 
expectativas no paraiso imigraram para a vida terrena; hoje, duqentos anos depois, as expectativas utópicas perderiam seu caráter secular e readotariam uma forma religiosa" (Habermas,1987, p.105).

Essa tese compartilhada por inúmeros autores contemporâneos é infundada, já que, como já foi dito, esgotou-se apenas uma determinada utopia cristalizada no passado em torno de uma sociedade do trabalho. Essa perplexidade contemporânea depois da falência de expectativas frente à sociedade do trabalho, seria a face visível de um dado sentimento coletivo que se manifesta frente à experiência de uma situação limite. Uma cultura que se acredita incapaz de reformular seu futuro, é incapaz até de acreditar que ele exista, e considera bem vindas aquelas teorias que abdicam de categorias positivas, pois sustentam sua compreensão da vida social e da vida coletiva de um modo geral, incluindo-se aí todos os seres vivos que compõem a biosfera, em uma eterna negação.

As açòes predatórias entào, poderiam ser circunscritas à anomia vivida pelo individuo que, segundo Franz Brüseke (1995, p.121-122) admite uma experiência limite caracterizada pela ausência mais ou menos completa da "capacidade espontânea de decidir entre o Bem e o Mal, o Certo e o Errado". A experiência anômica frente à natureza pode ser vista também como não dependente unicamente da sociedade desorganizada, mas de qualquer forma só é possível se não houver normas ou regras sociais que estabeleçam os limites e as possibilidades de relações entre sujeitos diferenciados. Se há normas e regras, a manifestação da ação predatória pode ser compreendida como a ruptura do acordo social.

Se a intenção aqui é rever algumas premissas que estão na base das relações possíveis entre cultura e natureza. Se o projeto ambientalista hoje pode ser visto como uma possibilidade de alargamento da esfera dos sujeitos portadores de direitos, e essa possibilidade pode ter tratada como uma objetivação possível da tensào entre desencantamento e reencantamento do mundo, cujos atores principais seriam, de um lado a aliança entre especia- 
listas e o Estado; e, de outro, os movimento religiosos em aliança com os grupos contra-cultura, seria particularmente arriscado levar às últimas consequências algumas das sugestões apontadas aqui.

O risco que representam é justificar teorias ou condutas políticas que abandonem de antemão a hipótese do próprio Habermas de que o neoconservadorismo ou esse novo anarquismo estejam apenas tentando mais uma vez, em nome de um adeus apressado à modernidade, revoltar-se contra ela, disfarçando sob a capa do novo, uma velha tradição que se opunha ao espírito de uma época, que se autocompreendia como atualidade, como renovação contínua.

O desafio do ambientalismo em seu sentido amplo, como projeto que ultrapassa uma disciplina cientifica ou qualquer setor social predominante, talvez seja colocar-se como o outro da razão instrumental e do projeto histórico social que a concretiza. Se esse é o sentido dado por eles, há possibilidade de consenso, mesmo que parcial; em contrapartida, seria conveniente não investir em rupturas apressadas, já que é necessário buscar de fato novos significados para essa natureza subjetivada, parceira em teias de relações múltiplas entre sujeitos diferenciados, mas sem abdicar da consciência histórica moderna, qual seja: "A modernidade não pode e não quer continuar a ir colher em outras épocas os critérios para sua orientação, ela tem que criar em si própria as normas pelas quais se rege" (Habermas, 1990, p.18).

Talvez fosse interessante lembrar ainda que o grande tema de autores como Habermas e Marcuse é a dominação, ou melhor dizendo, um tipo de agir que implica dominação, seja ela sobre a sociedade, seja sobre a natureza. Nossos intelectuais contemporâneos por sua vez, impregnados dessas idéias, buscam algum antidoto para a secularização e o fim do agir instrumental frente aos homens e à natureza.

O problema é que, por alguma razão de ser, esquecem que o espírito da revolta - alicerce de um mundo em constante transformação - é uma 
invenção das sociedades modernas, a partir da dessacralização do mundo. Ou em outros termos, "a existência do sagrado fixa as ações do indivíduo a certos trilhos e impossibilita assim, a revolta” (Brüseke, 1994, p.120).

É preciso lembrar também, que a emancipação e a autorganização só são possíveis no mundo contemporâneo a partir de centros que surgem nos domínios da prática cotidiana de comunicação, onde é possível desenvolver esferas públicas autônomas, passíveis de serem consolidadas como intersubjetividades, que ultrapassam o nível individual e são voltadas tanto à organização interna, quanto ao espaço público. Segundo Habermas (1990, p.331-333) a assimetria entre capacidades de auto-reflexão e autoorganizaçào que atribuimos às sociedades modernas em sua globalidade, repete-se no nível dos processos de formação da opinião e da vontade.

Assim, o fato de os movimentos sociais contemporâneos assumirem traços culturais altamente inovadores não é mero acaso. Sua razão de ser é a ameaça a identidades coletivas bem demarcadas. Embora, na maioria das vezes, tais identidades permaneçam vinculadas a particularidades ou especificidades excessivas, ou a condutas predominantemente conflitivas como apontou Hector Leis (1994), estas serão obrigadas cotidianamente a incorporar, em si mesmas, o conteúdo normativo da modernidade, que por sua própria natureza universalista e subjetiva, cria as condições mínimas ao diálogo entre diversidades no âmbito da sociedade e desta com o mundo natural.

Se o Estado nacional democrático inventado pela modernidade era até então a única possibilidade de formação de identidades que fogem a especificidades, aquele capaz de unir o particular ao universal, a alternativa das organizações não governamentais com o mesmo papel, pode ser muito mais eficaz à autorganização e emancipação da sociedade, ambos os movimentos necessários a um reordenamento das relações sociais frente à natureza. 
Seria conveniente reforçar, por fim, que o grande risco apontado aqui é fazer do irracionalismo nietzschiano o outro da razão instrumental. Seria impossivel deixar de reconhecer a advertência dos filósofos contemporâneos (Giannotti, 1987) acerca da necessidade de uma revisão profunda da própria razão clássica, já que a produção intelectual moderna, de Nietzsche à Escola de Frankfurt, passando por Foucault, foram todos extremamente eficazes em demonstrar a relação intima entre ela e o poder, em todas as esferas da vida, o que evidentemente explica a profunda crise por que passa atualmente. Mas em contrapartida, esta recusa consensual deve encontrar suas armas no seio de sua própria consciência, único locus possível para o autoconhecimento.

Essa visão dicotômica entre racionalismo/irracionalismo, herança da filosofia clássica kantiana não pode mais ser levada em conta. Seria possível ainda hoje acreditar na existência de um fosso profundo $\mathrm{c}$ intransponivel entre razão, entendimento e sensibilidade? A única resposta possível a essa questão agora é que essa oposição clássica perdeu o sentido; por isso, o programa reformador postulado pelos movimentos de herança da contracultura, de combater a razão a qualquer custo parece mais perigoso do que o seu outro, já que abre mão da premissa básica da mudança dada pelas possibilidades de autoconhecimento.

De qualquer forma, talvez fosse mais criterioso investir na distinção fundamental entre pelo menos dois tipos de racionalização, que é na verdade o ponto de partida do pensamento de Habermas. No nível da ação racional-referente-a-fins, que já forçou o reordenamento institucional e de setores parciais da sociedade, esta ainda pode expandir-se, mesmo que em certa medida. Mas esse desenvolvimento das forças produtivas pode tornar-se um potencial de liberação somente se nào substituir a racionalização na esfera político-institucional. Esta deve ser a esfera da ação intersubjetiva mediada simbolicamente pelo entendimento, possível somente através da dimuição dos instrumentos de controle social e político. 
Essa distinção fundamental talvez permitisse ao ambientalismo contemporâneo, como o permitiu a Habermas, tomar o paradigma do diálogo como o padrão de medida de uma racionalidade emancipatória. Evidentemente é difícil conseguir essa proeza, através de uma cultura exausta de si mesma. Mas, mesmo assim, seria conveniente aceitar o grande desafio comum de investir na discussão pública sem restrições e isenta de dominações, acerca de normas e princípios que orientem a ação em todos os níveis, em todos os processos políticos de formação de vontade. Esse desafio é comum aos neoromânticos, militantes e paragovernamentais.

$O$ ambientalismo contemporâneo, em seu sentido amplo, tanto no Brasil como nos países ricos, tem procurado construir espaços públicos para organizar a intersubjetividade cotidiana, onde a racionalização é possível e as normas sociais podem encontrar a legitimidade necessária e verdadeira. Essa sim parece ser a única estratégia em que a racionalização apresenta-se como possibilidade emancipatória. $O$ curioso disso tudo é que apenas os neoromânticos tem como reivindicação primordial a expansão da racionalização em direção à da vida privada. As vertentes holistas do ambientalismo, construindo-se na alteridade à razão instrumental, despedem-se do público e invadem cotidianamente a vida privada, reordenando hábitos $\mathrm{e}$ condutas individuais para alcançar um modo de vida pós-materialista, que por princípio seria sustentável do ponto de vista econômico, ecológico e espiritual.

De qualquer forma, se a preocupação dos neoromânticos é buscar um outro conteúdo normativo para a vida social contemporânea, em uma relação estreita com a biosfera, a partir de uma relação de alteridade frente ao projeto histórico-social da modernidade, seu diálogo com os outros grupos pode ser muito proveitoso, mas a primeira pergunta que estes poderiam colocar-lhe seria se a condição necessária à valorização da natureza estaria nela mesma, através de seu reencantamento? Ou em contrapartida, esta condiçào estaria no conteúdo normativo da própria sociedade, quando esta 
se pensa, através da herança desse tempo, como o lugar de permanência de sujeitos conscientes de seus direitos, estes sim pressupostos do sentimento de revolta? Este não pareceria o caminho mais próximo e adequado para a subjetivação da natureza em curso, nessa modernidade inacabada?

\section{BIBLIOGRAFIA}

ALFORD, R. \& FRIEDLAND, R. 1975. "Political participation and public policy". Annual Review of Sociology. vol. 1.

BASQUEIRO, M. \& REIS, J. 1987. "Participação e espaço imaginário". Revista Brasileira de Ciências Sociais, vol. 1, $\mathrm{n}^{\circ}, 3$

BAYLIS, T. 1978. "The faces of participation: a comparative perspective". Political Participation in Latin America. Vol. 1. Holmes \& Meyer Publishes Inc.

BENEVIDES, M.V. 1991. A cidadania ativa. Sào Paulo: Ed. Ática.

. 1994. "Democracia e cidadania" in: VILLAS-BOAS, R. "Participação popular nos governos locais". Polis. no. 14. São Paulo: Publicações Polis.

BRANDÃO, C.R. 1994. Somos as águas puras. Campinas: Papirus.

BRÜSEKE, F. 1994. A lógica da decadência. São Paulo. no prelo.

CARLING, A. 1986. "Rational choice marxism". New Left Review. $\mathrm{n}$ '. 160.

CITTADINO, G. 1988. "Movimentos sociais urbanos. Crise da política c democratização". Ciências Sociais Hoje, 1988. São Paulo: Vértice.

DURHAM, E. 1984. "Movimentos sociais: a construção da cidadania". Novos Estudos. $n^{\circ} 10$, CEBRAP.São Paulo: Ed. Ática.

FERREIRA, Leila C. 1992. Estado e Ecologia: novos dilemas e desafios. Tese de Doutorado em Ciências Sociais, IFCH/UNICAMP. Campinas.

FERREIRA, Lúcia C. . 1993. Os fantasmas do vale: a questão ambiental e a cidadania. Campinas: Editora da Unicamp.

FRIEDLAND, E.I. 1974. Introduction to the concept of rationality in political science. New York: Geneval. 
GALTUNG, J. 1984. "Los azules y los royos, los verdes y los pardos: una evolución de movimentos politicos alternativos". Boletim de Ciências Sociais. FLP/ UFSC, $\mathrm{n}^{\circ}$. 34. Florianópolis.

GIANNOTTI, J.A. 1987. "O tema da ilustraçào em três registros". Novos Estudos. CEBRAP, São Paulo, pp.3-15.

HABERMAS, J. 1980. "Técnica e Ciência enquanto Ideologia". Os Pensadores. São Paulo: Abril Cultural. 1987. "A nova intransparência". Novos Estudos. CEBRAP. São Paulo, n. 18. pp.103-114.

.1988. Teoria de la accion comunicativa. 2 ed. Madrid: Ed.

Taurus.

1989. Teoria de la acción comunicativa: complementos e estudios previos. Madrid: Ed. Catedra.

1990. O discurso filosófico da Modernidade. Lisboa: Publicaçōes Dom Quixote.

HORKHEIMER, M. \& ADORNO, T. 1980. "Conceito de Iluminismo". Os Pensadores. São Paulo: Abril Cultural

JACOBI, P. 1989. Movimentos sociais e políticas puiblicas. São Paulo: Cortez.

KRISCHKE, P.J. 1987. "Movimentos sociais e transição política: Contribuições da democracia de base" in: SCHERER-WARREN, I. \& KRISCHKE, P.J. 1987. Uma revolução no cotidiano? Os novos movimentos sociais na América do Sul. São Paulo: Brasiliense.

LEIS, H. 1994. Globalização e Democracia após a Rio-92. Trabalho apresentado GT Ecologia, Política e Sociedade. in ANPOCS, Caxambu, mimeo.

MACCORMICK, J. 1992. Rumo ao paraiso: a bistória do movimento ambientalista. Rio de Janeiro: Relume Dumará.

MIRANDA, J.C.R. 1979. O Plano Trienal, o canto do cisne do nacionaldesenvolvimentismo. Campinas: UNICAMP. Dissertação de Mestrado. Instituto de Economia, Universidade Estadual de Campinas, 1979. MOISÉS, J.A. 1985. Cidade, povo e poder. São Paulo: Paz e Terra 
NUNES, E. \& JACOBI, P. 1985. "Movimentos populares urbanos, poder local e conquista da democracia" in: MOISÉS, J.A. Cidade, povo e poder. São Paulo: Paz e Terra.

1989."Carências urbanas, reivindicações sociais e valores democráticos". Lua Nova. n. 17. São Paulo: CEDEC.

OFFE, C. 1984."Critérios de racionalidade e problemas funcionais da ação político-administrativa" in : OFFE, C. Problemas estruturais do estado capitalista. Rio de Janeiro: Tempo Brasileiro.

OPHULS, W. 1977. Ecology and the politics of scarcity. San Francisco: Freeman \& Company. W.H..

PAEHLKE, R.C. 1989. Environmentalism and the future of progressive politics.

New Haven: Yale University Press.

PIERUCCI, A.F. 1994."Ciladas da diferença". Tempo Social. São Paulo, vol.2, $\mathrm{n}^{\circ} 2$, USP.

PRZEWORSKI, A. 1988. "Marxismo e escolha racional". Revista Brasileira de Ciências Sociais. São Paulo. Vol. 3, nº. 6.

ROEMER, J.E. 1989. "O marxismo da escolha racional: algumas questões de método e conteúdo”. São Paulo: Lua Nova.. n. 19.

ROUSSEAU, J.J. 1978. O contrato social. São Paulo: Ed. Cultrix

SCHERER-WARREN, I. \& KRISCHKE, P.J. 1987. Uma revolução no cotidiano? Os novos movimentos sociais na América do Sul. São Paulo: Brasiliense.

. 1987. "O caráter dos novos movimentos sociais" in: SCHERERWARREN, I. \& KRISCHKE, P.J. 1987. Uma revolução no cotidiano? Os novos movimentos sociais na América do Sul. Sào Paulo: Brasiliense.

SERRES, M. 1991. O contrato natural. Rio de Janeiro: Editora Nova Fronteira.

TELLES, V.S. 1987. "Movimentos sociais: reflexões sobre a experiência dos anos 70" in: SCHERER-WARREN, I. \& KRISCHKE, P.J. 1987. Uma revolução no cotidiano? Os novos movimentos sociais na América do Sul. São Paulo: Brasiliense. 
1994. "Sociedade civil, direitos e espaço público". São Paulo: Publicações Polis.

THOMAS, K. 1988. O bomem e o mundo natural. São Paulo: Companhia das Letras.

VIOLA, E. 1991. "Movimento ambientalista". Relatório do Brasil na CNUMAD. Brasília: CIMA.

. 1992. "A dinâmica do ambientalismo e o processo de globalização”. São Paulo: São Paulo em Perspectiva. vol. 6, n 1. . \& LEIS, H. 1992. "A evolução das políticas ambientais no Brasil, 1971-1991" in HOGAN, D. (org.) Dilemas socioambientais e desenvolvimento sustentável. Campinas: Ed. Unicamp.

ZALUAR, A. 1992. "Exclusão social e violência". Sociedade civil e educaf̧ão. Campinas: Papirus. 